\title{
Defining Paradigms for Effective Industry Institute Collaboration
}

\author{
Ameet Chavan \\ Department of Electronics and Communication Engineering \\ Sreenidhi Institute of Science and Technology \\ Hyderabad, INDIA \\ e-mail: ameetchavan@gmail.com
}

\section{Bhujanga Rao Sanapala}

Department of Electronics and Communication Engineering

Sreenidhi Institute of Science and Technology

Hyderabad, INDIA

e-mail: sbrao@sreenidhi.edu.in

\begin{abstract}
Low employability and poor quality of today's graduating engineers is the issue of huge concern for sustaining the economic growth and country's progress. Both the issues have arisen due to an existing gap in acquiring necessary technical skills by the engineers, which are required by the hiring industry. This problem has to be addressed by the synergetic efforts of the institutes and industries - two entities which play the vital role of supply and demand. For enabling a bright future to the next generation it is important that this association is more effective with active collaboration. The paper makes an earnest effort in suggesting and identifying the key areas for industry-institute collaboration.
\end{abstract}

Keywords-Skill Gap, Engineering Education, Industry-Institute collaboration

\section{Introduction}

"There is a big gap between the supply and demand of engineering graduates today in terms of skill set and practical knowledge" - rhetoric put across now a days by all engineering education experts and industry managers. Industry says there is no dearth of jobs for good engineers and Institute says there is no dearth of qualified engineers. But the big question often asked is, why institutes fail in producing industry ready engineers. The accepted fact is that a big gap exists between the two entities in terms of expectations and deliverables. The stake holders are all aware of this gap and have been trying hard to bridge. The issues involved in this process are not simple to address but also not so complicated that they cannot be solved. The paper attempts to identify some of the existing issues and propose some tangible measures for corrective action.

Before addressing the core issue of industryinstitute collaboration the authors would like to put forth some of the fundamental problems that have contributed to the setback. Drastic increase in the number of engineering institutes in India, over 5000 colleges with total intake crossing over 1.5 million annually, this includes IITs, NITs, Central/Deemed Universities and Private affiliated colleges [1]. This expansion in enabling technical education has resulted in serious quality compromise which is essential for securing alliances and collaborations.

"To improve is to change; to be perfect is to change 
often." -Winston Churchill. In modern education system the software tools are prevailing in all science and engineering disciplines. So every engineering graduate must be knowledgeable and familiar with the specialized software tools designed for their area. Even those graduates aspiring to pursue higher education or planning to start industry are required to keep abreast of the latest developments in software. The engineering education is in a viscous circle, today the teachers and institutes who impart the knowledge and skills are themselves not familiar with the software tools that keep changing with time. This insufficiency primarily is due to the lack of continuous exposure to the industry and lack of awareness of the industry needs and expectations among the faculty. These deficiencies are there in every engineering discipline. Though there is no quick fix solution to these issues, the challenges are well debated and discussed on numerous forums. The authors, who had several opportunities to participate and contribute towards this cause, would like to share and suggest their views in this paper.

\section{Existing Scenario}

Currently, in the Electronics and Semiconductor industry, India has been major consumer and not manufacturer. As estimated by Indian Electronics and Semiconductor Association (IESA), the current Indian electronics import is around $\$ 40 \mathrm{~B}$ and by the year 2020 it is projected to go beyond $\$ 400 \mathrm{~B}$, surpassing the country's crude oil import [2]. This scenario is projected for all major manufacturing sectors and will hamper the country's economic growth. Though the growth in globalization and in the number of MNC's having their base in India do contribute towards strengthening of engineering colleges, the fact is that most of the hiring on the campuses is predominantly by the IT industry. So far this has been considered as boon but will prove disastrous for the core industry. Typically, hiring in the core engineering studies has reduced and is not lucrative enough for fresh engineering graduates. Realizing the dire consequences, of late there has been a lot of talk and concern expressed with some initiatives taken by CII, TIE, AICTE, MHRD, IESA, TEQIP-World Bank etc.

The topics in discussion in every engineering college and events organized nationally are IndustryInstitute Interaction, Industry Collaboration, Industry training of faculty and Industrial research and consultancy. These events have been successful mostly in creating awareness but unfortunately; the final recommendations of these meetings are neither fully implementable nor partly implementable without proper tools. Some of the reasons and techniques are discussed in the following sections IV and $\mathrm{V}$.

In order to have effective industry-institute collaboration roles are defined for each and every stake holder that includes: Regulatory bodies, Institute management, Teachers, Students, Alumni, Parents, Neighboring industry and Major campus recruiting companies. The contributions and practices for each stake holder are discussed in the subsequent sections. These recommendations are based on the exposure and experience of the authors gained through participation in several conferences, workshops and seminars.

It is hoped that the views and suggestions for the improvement of the engineering education will be considered seriously by the major stake holders Institute and Industry.

\section{Practices For Institute}

Innovation propels industry and market which in turn leads to expansion and hiring as depicted in Fig 1. Academia needs to understand this simple process and play a vital role by joining this process. Innovation is not a few persons responsibility but should be engrained in the institute's DNA. Many developed country universities, primarily the USA, have been front runners with their R\&D and making significant contributions to industry innovation. On the other hand Indian institutes have been producing only job

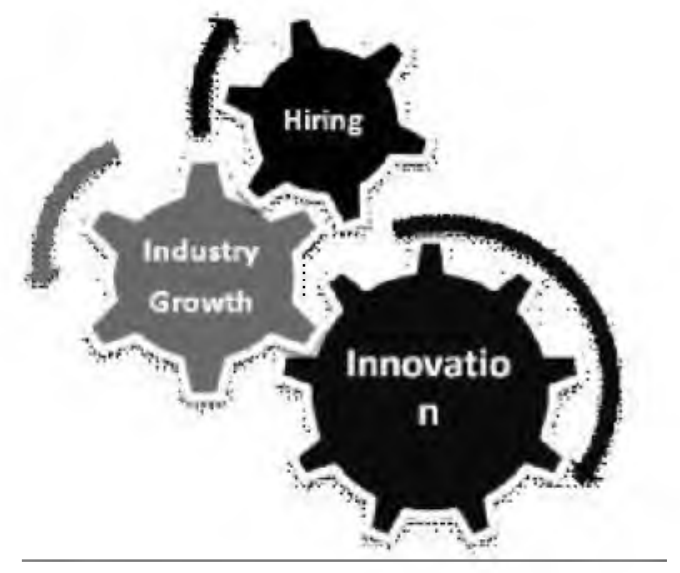

Figure 1: Relationship between innovation, industry growth and hiring 
seekers and contributions leading to industry innovation and entrepreneurship has been very dismal. Research and Innovation are the key parameters to ascertain high quality in country's higher education system. In the Indian context, the situation is alarming as India's share in world researchers stood at $2.2 \%$ in 2007 as against its neighbor China at 21\% [3]. Therefore, for long term sustainability and to ensure better prospects academia has to sincerely focus on research and innovation than traditional teaching.

India's need of the hour is to become self reliant in the technology development and manufacturing. "Make in India" is the new mantra to follow. This is only possible if indigenous talents competent in core areas are engineered. IESA has initiated an effort in this regard called the Core Initiative Group which focuses on talent development in the ESDM sector, making the engineers employable in the core area [4].

The paper makes an attempt to address the expectations of both industry and institute towards effective collaboration in the existing scenario of Indian education. There is no silver bullet that can provide an immediate solution to salvage the situation. Multiple techniques and approaches have to be implemented. The work presented discusses some practices, techniques and programs that institutes can undertake in order to find common grounds for effective collaboration.

\section{A. Application Based Teaching and Project Based Learning}

Experiential learning or project based learning is seriously lagging in India and cannot be readily adopted primarily due to two main reasons: higher number students $(60+$ per batch, most institutes running 3 to 5 sections per program) and lack of proper resources. The resources could be in terms of faculty expertise, laboratory equipment or availability of space, time and hence the intent. The situation is not encouraging in most Indian engineering education system as syllabus coverage is solely aimed for exam preparedness rather than emphasizing actual learning. This is even so true for an affiliated college, which operate with an added pressure to comply the almanac prepared by their guardian university. However, with outcome based education the future scenario looks optimistic as individual course outcomes are defined to achieve program outcomes and in turn the graduate attributes which attempts to ensure the best possible approach for engineering education. Further, the authors recommend that all engineering colleges under the outcome based education system should be endowed with some level of autonomy.

Interviewing panel from industry expect students to be strong in basic domain knowledge and be aware of applications in real world. The traditional teaching methodology has failed in developing this aspect and has become more of exam preparation education. The much cherished part of the engineering educationlearning through discovery and experience has taken a back seat. Today's engineering is going through a high time where experts have to reinvent methodologies to bring back the relevance. Reference [5] published a ground breaking study on teaching activities that support different aspects of the learning cycle based on Concrete Experience, Reflective Observation, Abstract Conceptulization and Active Experimentation, as shown in figure 2. To achieve application based teaching institutes can incorporate applications for every important concept with a hierarchal approach signifying the concept in the entire system design.

Learning is the process of developing individual's point of view beyond books. Project based learning enables a dynamic approach for students to learn

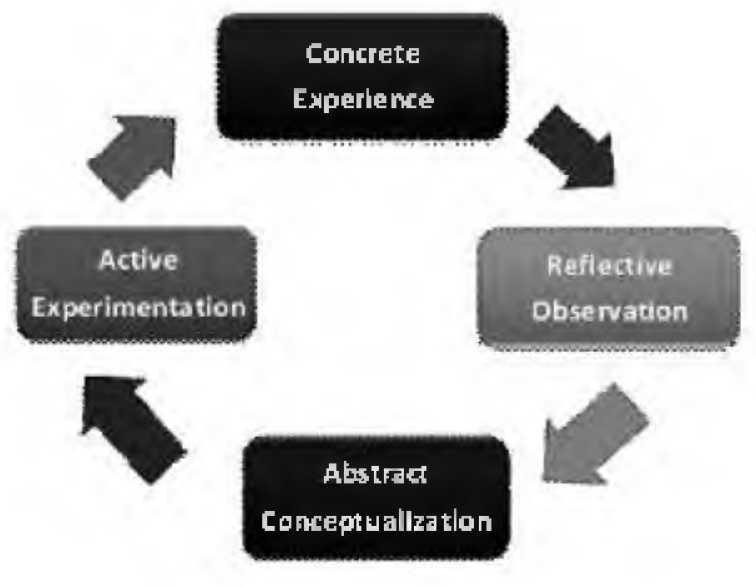

Figure 2: Holistic model of the learning process

concepts. With this methodology students apart from concreting their concepts will also be able to develop their basic research skills, that involves - exploring, investigation, understanding and project management.

Project based learning is the best way to integrate practical approach in the curriculum. This 
methodology is adopted for almost all engineering courses in the USA. In fact for most courses two-third of the time is spent in the class room and remaining one-third time is dedicated for project implementation, whereby students learn by designing and simulating the problem. Further, emphasis should not only be on functional correctness but also on specification analysis. This enables an excellent opportunity to students to get interested and connect to their core study area and aspire to pursue a career in the field.

\section{B. Embracing Startups and MSMEs}

Institutes should explore collaborating with startups and MSMEs as both parties can customize activities that they can effectively commit to which may not be feasible with big MNC companies. Some of proposed activities are training, internships, resource sharing, consultancy and joint research proposals.

\section{Technology Update Events and Student Clubs}

The institute should organize on regular basis technology update events for the benefit of the faculty and students. Technical seminars should be incorporated as a mandatory course, with reduced credits, to bring seriousness in participation. The resource persons from industry and premier colleges could be invited as guest lecturers. Faculties pursuing active research or doctoral studies could also be encouraged to participate and contribute in such events.

\section{Utilizing Industry University Programs}

The University Program from industries provides means for institutes to introduce and use industry technologies in teaching and research. The University Program offer institutes and educators discounted tools, free products, and lab donations to promote their technology. This is an excellent way for both to engage and create a win-win situation. Many University Programs collaborate with specialists from academics to develop and deliver top-quality teaching materials. University Program helps in developing inhouse workshop materials, teaching users how to use the tools and technologies in the most efficient ways. These workshop materials are accessible to academics to use in classes in their original forms and/or extend with additional material. Many University Programs also get actively involved in research projects based on industry's technologies. With present University Programs faculties can collaborate across countries on developing curriculums and access industry's rich teaching repository.

\section{E. Alumni Strength}

Numerous reputed private institutes within the country are in service of providing engineering education for decades but have failed to tap in this vital network resource - The Alumni. Many successful alumni who have climbed up the corporate

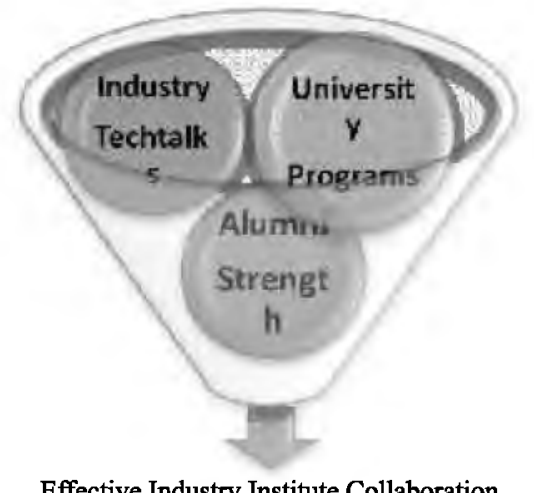

Fig. 3: Ingredients for Effective Collaboration

ladder and occupying important positions can patronage institutes. They can provide valuable aid in developing synergetic collaboration with their industry. Establishing a dedicated and active alumni association will further serve as a major network source for institutes in promoting their students for internships and faculties for training.

\section{F. Need Based Curriculum}

A continuous update approach needs to be adopted by the institutes with regard to curriculum and faculty training. Curriculum update should be need based and electives offered should be tailored to requirements of the industry. There may be dearth of faculties in the specialized advance topics of the elective and help could be sought from industry in form of experienced engineers visiting as faculties. For which the classes could be organized as per the expert convenience. Institutes should make an earnest effort to exposing students to industry culture and work environment by organizing regular field trips.

\section{G. Incentives to Teachers}

Research and Innovation can be imbibed in the teachers using a suitable mechanism for motivating 
teachers in this regard. Providing seed money for in house projects and research with the outcomes published in conferences or journals. Provide additional incentives for faculties and research scholars acquiring external grants. Some concrete efforts are also required for increasing the number of teachers who will also be involved in research and innovation in addition to teaching. Provide balanced work assignment where in the teacher may opt for assessment either based only on teaching and research or research alone.

\section{H. Foreign Partnership For Education and Research}

Global partnership of Indian institutes with foreign institutes has been the latest trend which is primarily based on either offering an integrated M.S program or finishing school with final year of the UG program to be completed in the foreign university. Further, the institutes can collaborate or register for paid services on using courseware developed by subject experts. Many USA universities like Purdue, MIT, Stanford, Harvard, Princeton, etc. offer specialized courses for faculties to enhance their knowledge that provide access to online labs and tools.

\section{Practices For Industry}

Industry priorities are channelized and deal with many complexities that involves cost, time, manpower and policy uncertainty. Interaction and collaboration with educational institutes does not fall in their priority list. This activity is carried on as a goodwill gesture rather than a responsibility. However, the industry is not to blame entirely for this attitude as they don't find institutes in the same level or close enough to make an active partnership. However, the authors in this section suggest following practices which the industry can adopt to raise the institute on the same plateau.

\section{A. Faculty Internship Programs}

The future of engineering education today is affected due to outdated knowledge of faculties with little or no practical experience. The miserable situation existing today is that many faculties never had any exposure to industry and its practices, knowledge gained is mostly from book and sadly teach students from the books.

Industry should provide faculty internship as a responsibility to improve the quality of engineering education. For which the companies could reap the benefits later as they could hire more local talent who are ready to contribute on the same technology platform. Under faculty internship program, industry could take up following activities - exposure to state of the art equipment and technology, increasing awareness to future trends and training on specialized topics to develop electives.

\section{B. Adopting Institute Laboratories}

Local and major industries around the institute can consider adopting institutes laboratories serving advance courses. However, this does not mean sponsoring or donating equipments or software to the labs but playing the role of a mentor by providing a channelized technical insight in performing the experiments and aiding in understanding the application aspect. Further, Industry can support by creating virtual labs where students and faculties can access non-proprietary advanced tools to get hands on training on the latest technology. However, this could be implemented with a nominal fess to the institutes.

\section{Refining Research}

The quality of research of the candidate pursuing doctoral studies is at a very dismal state. The research work carried out has no significance; neither contributes to technology advancement that could be adopted by industry nor serves betterment of mankind in any form. This situation could be mitigated to some extent by having an industry expert as part of the panel member of the doctoral research committee.

\section{Contibutions From Other Stake Holders}

Without the contributions from all the stake holders this mission is hard to achieve. The responsibilities have to be shared by all and benefits could be reaped for generations to come. The crucial role of each stake holder is discussed in the following sub-sections.

\section{A. Governing Bodies and Research Funding Agencies}

The quality of the incoming students to higher educational institutes must be ensured through suitable reforms right from the primary school level.

The number institutes that are permitted to open in the region should be based on the population needs 
and available industry infrastructure. This will also ensure even expansion of engineering colleges throughout the country. However, reports on higher education are already suggesting that a saturation limit has been attained and perhaps the only task remaining to do is to improve the quality.

\section{B. Management and Faculties}

"What is taught is not what is used in industry"-a generic comment received from most industry experts in a convention organized by the author's institute. The statement was in reference to the outdated syllabus that lacks in relevance to industry needs with regard to usage of modern tools and practices.

The authors propose an exercise to all engineering college management, to identify faculty strengths in each department with regard to their years of experience in teaching, funded research and relevant industry. This exercise would reveal the prevailing situation that most faculties have relatively less industry experience and are unfamiliar of the process, practices and design consideration adopted by an industry. They have relatively less exposure to latest technology and require hands on experience with the modern tools. To be an effective instructor a comprehensive knowledge has to be imparted to the student with regard to understanding of the concept followed with application example and project with latest tool.

The authors propose to UGC and institute management to adopt a 5:1:1 (Teaching : Funded Research : Relevant Industry) experience ratio distribution for every 7 years of experience claimed by the hiring faculty. This is in addition to the Academic Performance Indicators (APIs) score used for recruitments and Career Advancement Schemes (CAS) promotions existing for university and college faculties.

Management has to encourage faculty to go to industry periodically for training and exposure; employ qualified persons with rich industry background and encourage competent industry people to develop environment of industry in the campus. Initially, some investment is necessary; students may be motivated to contribute for creating an industry environment on campus or approach appropriate funding agencies. Management has to regulate the quality of incoming students under the Bcategory admissions. An aptitude test to such aspirants may help to some extent. Management has to keep track and update a complete record of its alumni.

Faculties must proactively pursue to bridge the gap between the curriculum and the practical applications in the industry. For which all senior and research pursuing faculties must actively participate in industrial training. The management should make it mandatory for all teaching staff and faculties to undergo such training at least once in a year.

\section{Alumni}

Outgoing students are the spokesman of the college. It is the alumni who have to give something back to their institute. There are alumni association of institutes in various cities and countries which meet and discuss the status and new developments from time to time. An alumnus has to take initiatives to participate in the curricular and other developmental activities of the institute. Alumni are among the right stake holders to suggest ways and methods for bridging gaps between industry and institute.

\section{Parents}

Many parents and their relatives run industrial establishments, small or medium scale. Such parents with means should share their experiences with aspiring students. They should be part in the development of student's career by actively participating in suggesting activities beyond curriculum. Apart from regular monitoring on the ward's progress, parents should also seek regular updates from the management with regards to activities organized towards enhancement of industry collaborations and improving hiring prospects of their ward. Willing parents should identify the skill sets needed for their wards to develop career in their chosen area.

\section{E. Students}

Students should be sincere in choosing endeavors that would lead to building a career. This involves listing activities required to gain skills at various stages in their engineering program. Develop a strong sense of future - that is to secure a dream job or become a successful entrepreneur. Understand the expectations of industry through regular interactions with alumni, industry people and immediate graduating seniors. 


\section{Conclusion}

The authors have suggested avenues for active collaboration between institute and industry which could be undertaken by all stakeholders including accrediting and governing agencies. Efforts have to be made with a sense of urgency in implementing the suggested steps to mitigate the skill gap. For institutes to sustain in long run useful research contributing to the society needs and the future enhancement of technology has to be promoted. The authors have proposed 5:1:1 experience ratio for faculty recruiting in addition to the API score. Silver lining exists in the form of agencies like CII, TEQIP, IESA, etc that are willing to offer help to have a mutual beneficial outcome for the institute and industry.

\section{Acknowledgment}

The authors acknowledge the contributions and encouragement of Dr. Poreddy Narasimha Reddy, Executive Director, SNIST.

\section{References}

[1] Prof. O.R.S Rao, "Engineering Education in India at Crossroads", The Journal of Engineering Education, April 2012

[2]Sanjeev Keskar, IESA Report- 2013. http://www.iesaonline.org/events/presentations.ht $\mathrm{ml}$

[3] Prof. O.R.S Rao, "Outcome Based Engineering Education-Need of the hour", The Journal of Engineering Education, July 2013

[4] Vivek Pawar, Nagaraj Subramanyam, "Core Initiative Group - Talent Development in ESDM Sector", Jun 302013.

[5]David Kold, "Experiential Learning: Experience as the source of Learning and Development", Prientice-Hall, Inc, Englewood Cliffs, N.J 